\title{
Antidepressant use and risk of cardiovascular outcomes in people aged 20 to 64: cohort study using primary care database
}

\author{
Carol Coupland, ${ }^{1}$ Trevor Hill, ${ }^{1}$ Richard Morriss, ${ }^{2}$ Michael Moore, ${ }^{3}$ Antony Arthur, ${ }^{4}$ Julia Hippisley-Cox ${ }^{1}$
}

'Division of Primary Care,

School of Medicine, University

of Nottingham, Nottingham NG7

2RD, UK

Institute of Mental Health, Nottingham NG8 1BB, UK

${ }^{3}$ University of Southampton Medical School, Primary Care and Population Sciences, Aldermoor Health Centre, Southampton S016 5ST, UK

4 School of Health Sciences, Faculty of Medicine and Health Sciences, University of East Anglia, Norwich NR4 7TJ, UK

Correspondence to: C Coupland carol.coupland@nottingham.ac.uk Additional material is published online only. To view please visit the journal online.

Cite this as: $B M J$ 2016;352:i1350 http://dx.doi.org/10.1136/bmj.i1350

Accepted: 20 February 2016

\section{ABSTRACT}

OBJECTIVE

To assess associations between different antidepressant treatments and rates of three cardiovascular outcomes (myocardial infarction, stroke or transient ischaemic attack, and arrhythmia) in people with depression.

DESIGN

Cohort study.

SETTING

UK general practices contributing to the QResearch primary care database.

\section{PARTICIPANTS}

238963 patients aged 20 to 64 years with a first diagnosis of depression between 1 January 2000 and 31 July 2011.

\section{EXPOSURES}

Antidepressant class (tricyclic and related antidepressants, selective serotonin reuptake inhibitors, other antidepressants), dose, duration of use, and commonly prescribed individual antidepressant drugs.

\section{MAIN OUTCOME MEASURES}

First diagnoses of myocardial infarction, stroke or transient ischaemic attack, and arrhythmia during five years' follow-up. Cox proportional hazards models were used to estimate hazard ratios, adjusting for potential confounding variables.

RESULTS

During five years of follow-up, 772 patients had a myocardial infarction, 1106 had a stroke or transient ischaemic attack, and 1452 were diagnosed as having arrhythmia. No significant associations were found between antidepressant class and myocardial

\section{WHAT IS ALREADY KNOWN ON THIS TOPIC}

Depression is a common condition, and antidepressants-particularly selective serotonin reuptake inhibitors-are increasingly used in its treatment

Rates of cardiovascular disease are higher in people with depression, but whether different antidepressant treatments increase or reduce these rates is unclear High doses of certain antidepressants, including citalopram, can cause QT prolongation, which may increase the risk of arrhythmia, but this is not established

\section{WHAT THIS STUDY ADDS}

This study found no evidence that selective serotonin reuptake inhibitors as a class are associated with an increased risk of arrhythmia and stroke or transient ischaemic attack in people with depression aged 20 to 64

No evidence was found that citalopram is associated with a significantly increased risk of arrhythmia, even at high doses

Some indication was seen of a reduced risk of myocardial infarction for selective serotonin reuptake inhibitors, particularly fluoxetine infarction over five years' follow-up. In the first year of follow-up, patients treated with selective serotonin reuptake inhibitors had a significantly reduced risk of myocardial infarction (adjusted hazard ratio 0.58, 95\% confidence interval 0.42 to 0.79 ) compared with no use of antidepressants; among individual drugs, fluoxetine was associated with a significantly reduced risk $(0.44,0.27$ to 0.72$)$ and lofepramine with a significantly increased risk $(3.07,1.50$ to 6.26$)$. No significant associations were found between antidepressant class or individual drugs and risk of stroke or transient ischaemic attack. Antidepressant class was not significantly associated with arrhythmia over five years' follow-up, although the risk was significantly increased during the first 28 days of treatment with tricyclic and related antidepressants (adjusted hazard ratio 1.99, 1.27 to 3.13). Fluoxetine was associated with a significantly reduced risk of arrhythmia (0.74, 0.59 to 0.92$)$ over five years, but citalopram was not significantly associated with risk of arrhythmia even at high doses (1.11, 0.72 to 1.71 for doses $\geq 40 \mathrm{mg} /$ day).

\section{CONCLUSIONS}

This study found no evidence that selective serotonin reuptake inhibitors are associated with an increased risk of arrhythmia or stroke/transient ischaemic attack in people diagnosed as having depression between the ages of 20 to 64 or that citalopram is associated with a significantly increased risk of arrhythmia. It found some indication of a reduced risk of myocardial infarction with selective serotonin reuptake inhibitors, particularly fluoxetine, and of an increased risk with lofepramine.

\section{Introduction}

Depression is a common and debilitating condition, which is often treated with antidepressants. Depression increases the risk of cardiovascular outcomes, but controversy exists as to whether use of antidepressants, particularly selective serotonin reuptake inhibitors, increases or reduces the risk. ${ }^{12}$ This is important because antidepressants are one of the most commonly prescribed types of drug worldwide, and their use is increasing. ${ }^{3-5}$ In the United States, antidepressants were the third most commonly used prescription drug in 2005-08, and their use had increased by almost $400 \%$ compared with $1988-94^{6}$; in England, more than 53 million prescriptions for antidepressants were issued in $2013,{ }^{7}$ nearly a twofold increase compared with a decade earlier. ${ }^{8}$ More than half (54\%) of the prescriptions in England in 2013 were for selective serotonin reuptake inhibitors, including nearly 14 million prescriptions for the most commonly prescribed antidepressant citalopram. 
Theoretically, antidepressants such as selective serotonin reuptake inhibitors may have effects on coagulation, and some studies have explored their cardioprotective effect. These studies have tended to be underpowered and explored outcomes in secondary care or other selected populations. Randomised controlled trials of antidepressants tend to be short term and underpowered to detect effects on cardiovascular outcomes, and observational studies of cardiovascular outcomes show conflicting results and many have not accounted for depression and so are susceptible to indication biases. The observational studies have either been restricted to or predominantly included older people, so uncertainty exists about associations in a younger age group, although antidepressants are often prescribed for depression in adults of working age. Antidepressants may have differential effects on cardiovascular outcomes according to age. A meta-analysis of 13 observational studies found that use of selective serotonin reuptake inhibitors was associated with a $40 \%$ increased risk of stroke, but this was significant only in studies restricted to older age groups and no significantly increased risk was seen in studies with no age restriction, although none of the studies specifically focused on a younger age group. ${ }^{9}$ Similarly, for myocardial infarction, uncertainty exists about an association with selective serotonin reuptake inhibitors. A large observational study in people aged 65 and over with depression found an increased risk of myocardial infarction with selective serotonin reuptake inhibitors, ${ }^{10}$ whereas other studies in broader age groups have found no association or reduced risks, ${ }^{11-13}$ which could be a result of differing age ranges or indication biases.

The US Food and Drug Administration (FDA) issued a drug safety communication in 2011, stating that citalopram should not be prescribed at doses greater than $40 \mathrm{mg}$ per day, based on findings of QT interval prolongation in a study of 119 participants who received different doses of citalopram. ${ }^{14}$ The European Medicines Agency issued a similar safety warning in 2011. Further studies have reported QT interval prolongation with citalopram and also with some other antidepressants such as escitalopram and amitriptyline. ${ }^{15} 16$ QT interval prolongation can lead to arrhythmias including potentially fatal torsades de pointes, ${ }^{17}$ but few studies have specifically assessed risk of arrhythmia for different antidepressant drugs. A cohort study in predominantly older men of two different selective serotonin reuptake inhibitor antidepressants found significantly lower risks of arrhythmia for doses of citalopram over $40 \mathrm{mg} /$ day compared with doses of $1-20 \mathrm{mg} /$ day, with similar findings for sertraline. ${ }^{18}$ A cohort study based on claims data in the United States found no significant differences in risk of ventricular arrhythmia/sudden death for 20 types of antidepressant drug compared with paroxetine, except for a higher risk in mirtazapine users. ${ }^{19}$

Few observational studies of cardiovascular effects have examined associations with individual drugs, so evidence for specific commonly prescribed antidepressants is lacking, especially in younger people, as is evidence in relation to duration and dose. We therefore carried out a cohort study in people aged 20 to 64 to investigate the associations between different antidepressant drugs and the risk of myocardial infarction, arrhythmia, and stroke/transient ischaemic attack and also examined both dose and duration of use.

\section{Methods}

The cohort study was designed to estimate associations between antidepressant treatment and several different adverse outcomes including arrhythmia, myocardial infarction, and stroke or transient ischaemic attack. Full details of the study design, outcomes, and methods can be found in the study protocol..$^{20}$ Results relating to the epilepsy, suicide, and self harm outcomes have been published previously. ${ }^{2122}$

\section{Study cohort}

The study cohort was selected from a large primary care database (QResearch, version 34). At the time of the study, the QResearch database contained the anonymised longitudinal health records of more than 12 million patients from more than 600 general practices across the United Kingdom, which record data using the Egton Medical Information Systems (EMIS) medical records computer system. Recorded information includes patients' characteristics, clinical diagnoses, symptoms, and prescribed drugs.

The cohort included patients with a first computer recorded diagnosis of depression between the ages of 20 and 64 years at the time of diagnosis, from 1 January 2000 to 31 July 2011, as described previously. ${ }^{22}$ We identified patients with a diagnosis of depression by using diagnostic Read codes used in previous studies. ${ }^{102324}$ Read codes are the clinical codes used in general practice in the United Kingdom. Patients were eligible for inclusion if their diagnosis of depression occurred at least 12 months after their registration with a study practice and the installation date of their practice's EMIS computer system. We restricted our cohort to patients with a first recorded diagnosis of depression so that antidepressant prescribing during follow-up would not be influenced by any previous experiences and preferences that would be difficult to account for in the analyses. We used the 12 month inclusion criterion to ensure that the diagnosis of depression was not a retrospective recording of a previous diagnosis.

We excluded patients with a previous recorded diagnosis of depression; those with a diagnosis of schizophrenia, bipolar disorder, or another type of psychosis; and those who had received prescriptions for lithium or antimanic drugs. We also excluded patients if they had received prescriptions for an antidepressant before the study start date (1 January 2000), before their registration date, before they were aged 20, or more than 36 months before their first recorded diagnosis of depression. Temporary residents were also excluded.

The patient's study entry date was the earliest of the date of the first recorded diagnosis of depression or the 
date of the first prescription for an antidepressant. Participants in the cohort were followed up until the earliest of date of death, date of leaving the practice, or the end of the follow-up period (1 August 2012).

\section{Outcomes}

The three outcomes for these analyses were arrhythmia, myocardial infarction, and stroke or transient ischaemic attack. We identified patients with these outcomes if they were recorded either on their general practice record using the relevant Read codes or on their linked Office of National Statistics cause of death record using ICD (international classification of diseases) diagnostic codes, based on codes used in previous studies, ${ }^{25-27}$ as listed in the web appendix. For the analysis of each separate outcome, we considered only the first event and excluded patients with a previous diagnosis of the outcome recorded at baseline.

\section{Exposures}

We extracted information on all prescriptions for antidepressants during follow-up. We calculated the duration of each prescription by dividing the number of tablets prescribed by the number to be taken each day. ${ }^{22}$

For the main analyses, we grouped antidepressant drugs according to the four main classes in the British National Formulary: tricyclic and related antidepressants, selective serotonin reuptake inhibitors, monoamine oxidase inhibitors, and other antidepressants. We classified prescriptions for different antidepressant drugs on the same date as combined prescriptions.

We calculated the daily dose of each prescription by multiplying the number of tablets to be taken each day by the dose of each tablet, and we converted this to a defined daily dose to enable comparison of doses between antidepressant classes, using values assigned by the World Health Organization's Collaborating Centre for Drug Statistics Methodology (www.whocc.no/ atc_ddd_index). For some prescriptions, the dosing instructions were missing or not sufficiently detailed to allow calculation of a daily dose $(<5 \%$ of total prescriptions). We also assessed the 11 most frequently prescribed individual antidepressant drugs. ${ }^{10} 1922$

\section{Confounding variables}

We extracted data on variables considered to be potential risk factors for the cardiovascular outcomes or associated with the likelihood of receiving a particular antidepressant treatment, based on our previous study of antidepressants in people aged 65 or over. ${ }^{10}$ These were age at study entry (continuous); sex; year of diagnosis of depression (continuous); severity of index diagnosis of depression (categorised as mild, moderate, or severe, using the classification of Read codes for depression published by Martinez and colleagues ${ }^{23}$ and additional classification by a member of the study team (RM) of some Read codes for depression used in our study ${ }^{21}$ but not included in the study by Martinez); deprivation (Townsend deprivation score corresponding to the patient's postcode, in fifths); smoking status (non-smoker, ex-smoker, light smoker (1-9 cigarettes/ day), moderate smoker (10-19 cigarettes/day), heavy smoker ( $\geq 20$ cigarettes/day), not recorded); alcohol intake (none, trivial (<1 unit/day), light (1-2 units/day), medium (3-6 units/day), heavy (7-9 units/day), very heavy ( $>9$ units/day), not recorded); ethnic group (categorised into a binary variable of white/not recorded or non-white (comprising Indian, Pakistani, Bangladeshi, other Asian, black African, black Caribbean, Chinese, other including mixed)); comorbidities at baseline (individual binary variables for each of coronary heart disease, diabetes, hypertension, cancer, epilepsy/seizures, hypothyroidism, osteoarthritis, rheumatoid arthritis, asthma/chronic obstructive pulmonary disease, osteoporosis, liver disease, renal disease, obsessive-compulsive disorder); and use of other drugs at baseline (individual binary variables for each of antihypertensives, aspirin, statins, anticoagulants, non-steroidal anti-inflammatory drugs, anticonvulsants, hypnotics/anxiolytics, antipsychotics, bisphosphonates, oral contraceptives, hormone replacement therapy). In addition, for the arrhythmia and myocardial infarction outcomes, we adjusted for a diagnosis of stroke or transient ischaemic attack at baseline. We included year of diagnosis of depression as a confounding variable to account for changes in prescribing patterns over time.

\section{Statistical analysis}

We used Cox's proportional hazards models to estimate associations between the three outcomes and exposure to antidepressant drugs, treating antidepressant exposure as a time varying exposure to allow for patients starting and stopping and also changing between treatments during follow-up. We used robust standard errors to allow for clustering of patients within practices. We excluded patients from the analysis of each outcome if they had the outcome recorded at baseline. We classified patients as exposed to an antidepressant if no gaps of more than 90 days existed between the end of one prescription and the start of the next. If gaps of more than 90 days occurred, patients counted as exposed for the first 90 days and then unexposed for the remaining period. When patients stopped an antidepressant, we classified them as exposed for the first 90 days after the estimated date of stopping, so that outcomes occurring during withdrawal periods would be attributed to the antidepressant. The main analyses were based on the first five years of follow-up after study entry, and patients were censored at the earliest of five years after study entry, date of death, date of leaving the practice, or the end of the follow-up period in these analyses. We selected five years of follow-up for our main analyses as this would incorporate periods of long term treatment and also allow for more events to accrue than a shorter follow-up period would, so increasing the power of the study.

The analyses calculated unadjusted and adjusted hazard ratios for each antidepressant class (tricyclic and related antidepressants, selective serotonin reuptake inhibitors, other antidepressants, combined treatment) compared with periods of no antidepressant 
treatment. The unexposed reference category included periods of unexposed time in patients treated at other periods of time during follow-up, as well as person years from patients who received no antidepressant treatment throughout follow-up, so the hazard ratios compare rates of the outcomes between exposed and unexposed periods of time throughout follow-up. Patients who received monoamine oxidase inhibitors at any time were excluded from these analyses, as the number in this category was small. We excluded patients with missing deprivation scores from the adjusted analyses. Analyses were carried out for time varying exposures of prescribed daily dose (categorised as $\leq 0.5,>0.5$ and $\leq 1.0$, and $>1.0$ defined daily doses), and we calculated tests for trend within each drug class by using dose as a continuous variable. Periods of exposure time for which daily dose was missing were excluded from the analysis of dose. We did additional analyses for time since starting treatment (categorised as no use or treatment duration of 1-28 days, 29-84 days, or $\geq 85$ days) and time since stopping treatment (1-28 days, 29-84 days, and 85-182 days after the estimated date of stopping treatment) and for the 11 most commonly prescribed individual antidepressants, as in a previous study..$^{10}$ Individual antidepressants were further categorised by dose ( $\leq 1$ or $>1$ defined daily doses), and citalopram was also categorised as $\leq 20 \mathrm{mg} /$ day, 20-39 mg/day, and $\geq 40 \mathrm{mg} /$ day for an analysis of the arrhythmia outcome, in light of the FDA's drug safety communication. ${ }^{28}$

We used Wald's significance tests to identify significant differences between antidepressant classes and between individual antidepressant drugs. We tested for interactions between class of antidepressant and age and sex. We assessed the proportional hazards assumption by using log minus log plots.

As sensitivity analyses, we repeated the analyses including the entire follow-up period and did an analysis excluding patients who received no antidepressant prescriptions during follow-up. ${ }^{22}$ We repeated our main analyses using selective serotonin reuptake inhibitors as the comparison group for drug class, the middle dose category of selective serotonin reuptake inhibitors as the comparison group for drug dose, and citalopram (the most commonly prescribed antidepressant) as the comparison group for individual antidepressants.

We also did an analysis restricted to the first year of follow-up; we did this because we had some evidence of non-proportional hazards over five years of follow-up, and also this time period more closely reflected the average duration of treatment. As a post hoc analysis, we also estimated adjusted hazard ratios separately using interaction terms for the 0-1 years, 1-3 years, and 3-5 years after the start of follow-up to further investigate changes in hazard ratios over time. We did these analyses for drug class and for only the five most frequently prescribed antidepressants owing to the smaller numbers of events in the later time periods. To examine the effect of adjusting for different confounding variables, we did additional analyses entering the variables in blocks. As a post hoc analysis, we used a stratified Cox model, with stratification by general practice to compare with our main models using robust standard errors to account for clustering by practice.

We calculated absolute risks of the three outcomes over one year, accounting for the confounding variables by using the adjusted hazard ratios from the analyses based on one year of follow-up, according to the method described by Altman et al. ${ }^{29}$

We included all eligible patients in the database in our analyses to maximise power. We used a $\mathrm{P}$ value of $<0.01$ (two tailed) to determine statistical significance. We used Stata (v12.1) for all analyses.

\section{Patient involvement}

No patients were involved in setting the research question or the outcome measures, nor were they involved in the design or implementation of the study. No patients were asked to advise on interpretation or writing up of results. Patient representatives from the QResearch Advisory Board have advised on dissemination of studies using QResearch data, including the use of lay summaries describing the research and its results.

\section{Results}

The initial cohort included 327235 patients with a first diagnosis of depression made between the ages of 20 and 64, between 1 January 2000 and 31 July 2011. We excluded 88272 (27.0\%) patients because they had schizophrenia, bipolar disorder, or other psychoses; had been treated with lithium or antimanic drugs; or had received a prescription for an antidepressant before the study entry date, before age 20 , or more than 36 months before their date of diagnosis of depression. This left 238963 patients from 687 practices in the final study cohort.

The total length of follow-up was 1307326 person years. Among patients in the cohort 123038 (51.5\%) had at least five years of follow-up, with a median of 5.2 (interquartile range 2.5-8.2) years overall. The mean age of patients in the study cohort was 39.5 (SD 11.1) years, and 61\% were women (table 1). Townsend deprivation score was missing for 8201 (3.4\%) patients.

\section{Antidepressant treatment during follow-up}

During follow-up, 209476 (87.7\%) patients received a total of 3337336 antidepressant prescriptions. These comprised 2379668 (71.3\%) prescriptions for selective serotonin reuptake inhibitors, 533798 (16.0\%) for tricyclic and related antidepressants, and 422079 (12.7\%) for the group of other antidepressants. In addition, 156 patients had received a total of 1791 (0.05\%) prescriptions for monoamine oxidase inhibitors. There were 83784 combined prescriptions for two or more different antidepressant drugs prescribed on the same day. The median duration of treatment during follow-up was 221 (interquartile range 79-590) days.

Among a total of 3252633 prescriptions (with combined prescriptions counting as single prescriptions), 


\begin{tabular}{|c|c|}
\hline Characteristic & Value \\
\hline Female sex & $146028(61.1)$ \\
\hline Mean (SD) age, years & $39.5(11.1)$ \\
\hline \multicolumn{2}{|l|}{ Ethnic group: } \\
\hline Recorded & $136624(57.2)$ \\
\hline White/not recorded & $227451(95.2)$ \\
\hline Non-white & $11512(4.8)$ \\
\hline \multicolumn{2}{|l|}{ Depression severity (index diagnosis): } \\
\hline Mild & $171208(71.7)$ \\
\hline Moderate & $59140(24.8)$ \\
\hline Severe & $8615(3.6)$ \\
\hline \multicolumn{2}{|l|}{ Smoking status*: } \\
\hline Non-smoker & $110849(47.5)$ \\
\hline Ex-smoker & $35132(15.1)$ \\
\hline Current light smoker & $24104(10.3)$ \\
\hline Current moderate smoker & $40546(17.4)$ \\
\hline Current heavy smoker & $22659(9.7)$ \\
\hline Not recorded & 5673 \\
\hline \multicolumn{2}{|l|}{ Alcohol consumption*: } \\
\hline Non-drinker & $55253(27.2)$ \\
\hline Trivial (<1 unit/day) & $77579(38.2)$ \\
\hline Light (1-2 units/day) & $51310(25.3)$ \\
\hline Moderate (3-6 units/day) & $14482(7.1)$ \\
\hline Heavy (7-9 units/day) & $2174(1.1)$ \\
\hline Very heavy ( $>9$ units/day) & $2391(1.2)$ \\
\hline Not recorded & 35774 \\
\hline \multicolumn{2}{|l|}{ Townsend deprivation score in fifths*: } \\
\hline 1 (least deprived) & $45021(19.5)$ \\
\hline 2 & $46207(20.0)$ \\
\hline 3 & $48293(20.9)$ \\
\hline 4 & $47063(20.4)$ \\
\hline 5 (most deprived) & $44178(19.1)$ \\
\hline Not recorded & 8201 \\
\hline \multicolumn{2}{|l|}{ Comorbidities at baseline: } \\
\hline Coronary heart disease & $4109(1.7)$ \\
\hline Diabetes & $7371(3.1)$ \\
\hline Hypertension & $17217(7.2)$ \\
\hline Stroke/transient ischaemic attack & $1741(0.7)$ \\
\hline Arrhythmia & $2373(1.0)$ \\
\hline Any cancer & $3810(1.6)$ \\
\hline Asthma/chronic obstructive pulmonary disease & 31816 (13.3) \\
\hline Epilepsy/seizures & $3325(1.4)$ \\
\hline Hypothyroidism & $5267(2.2)$ \\
\hline Obsessive-compulsive disorder & $494(0.2)$ \\
\hline Osteoarthritis & $7228(3.0)$ \\
\hline Osteoporosis & $867(0.4)$ \\
\hline Liver disease & $698(0.3)$ \\
\hline Renal disease & $549(0.2)$ \\
\hline Rheumatoid arthritis & $1301(0.5)$ \\
\hline \multicolumn{2}{|l|}{ Drugs at baseline: } \\
\hline Anticonvulsants & $2672(1.1)$ \\
\hline Antihypertensives & $25344(10.6)$ \\
\hline Antipsychotics & $836(0.4)$ \\
\hline Anticoagulants & $1073(0.5)$ \\
\hline Aspirin & $7159(3.0)$ \\
\hline Bisphosphonates & $854(0.4)$ \\
\hline Hypnotics/anxiolytics & $11354(4.8)$ \\
\hline Non-steroidal anti-inflammatory drugs & $12725(5.3)$ \\
\hline Statins & $10823(4.5)$ \\
\hline Oral contraceptivest & $27396(18.8)$ \\
\hline Hormone replacement therapy $\dagger$ & $7207(4.9)$ \\
\hline
\end{tabular}

citalopram was the most commonly prescribed antidepressant (1023255 (31.5\%) prescriptions) followed by fluoxetine $(778285 ; 23.9 \%)$, and then amitriptyline (236416; 7.3\%). Supplementary table A shows numbers of prescriptions for the 11 most commonly prescribed antidepressants, with information on prescribed daily doses. Distributions of baseline characteristics according to the first antidepressant prescribed for these 11 drugs have been presented in a previous paper. ${ }^{22}$

\section{Associations with arrhythmia}

At baseline, 2373 patients had an existing diagnosis of arrhythmia. We excluded these patients from analysis of the arrhythmia outcome, along with the patients who received prescriptions for monoamine oxidase inhibitors, leaving 236434 patients in the analysis cohort. During the first five years of follow-up, 1452 new diagnoses of arrhythmia were made, giving an incidence rate of 16.2 per 10000 person years (20.1 per 10000 in men and 13.8 per 10000 in women).

We found no significant associations with arrhythmia (at $\mathrm{P}<0.01$ ) for any of the drug classes over five years compared with periods of no antidepressant treatment, as shown in table 2, although we saw some indication of a reduced hazard ratio for selective serotonin reuptake inhibitors (adjusted hazard ratio 0.84, 95\% confidence interval 0.73 to $0.97 ; \mathrm{P}=0.02$ ) compared with no current use of antidepressants. In a direct comparison with selective serotonin reuptake inhibitors (supplementary table B), we found a significantly increased rate for the group of other antidepressants (adjusted hazard ratio $1.44,1.12$ to 1.85$)$.

We found no significant trends with dose in the three drug classes (table 2). A significant increase in the rate of arrhythmia occurred in the first 28 days after starting treatment with tricyclic and related antidepressants (adjusted hazard ratio 1.99, 1.27 to 3.13; $\mathrm{P}=0.003$ ), as well as a significant reduction from 84 days after starting selective serotonin reuptake inhibitors $(0.78,0.66$ to 0.92; $\mathrm{P}=0.004)$.

In the analysis of the 11 most commonly prescribed drugs, we found significant differences between the drugs overall $(\mathrm{P}=0.004)$ but no significant difference between the four tricyclic and related antidepressants $(\mathrm{P}=0.22)$ or the five selective serotonin reuptake inhibitors $(\mathrm{P}=0.39)$, although we saw a significantly decreased risk for fluoxetine (adjusted hazard ratio 0.74, 0.59 to 0.92; $\mathrm{P}=0.008$ ) and some indication of an increased risk for lofepramine (1.67, 1.01 to $2.76 ; \mathrm{P}=0.05)$ compared with periods of no antidepressant treatment (fig 1).

In an analysis of dose for individual antidepressants (table 3), rates of arrhythmia were not significantly increased for higher doses of citalopram (adjusted hazard ratio $1.08,0.74$ to 1.57 , for doses $>20 \mathrm{mg}$ /day) or escitalopram (1.06, 0.52 to 2.16 , for doses $>10 \mathrm{mg} /$ day), but we found a significant increase for lower doses of lofepramine (3.89, 1.92 to 7.90 , for doses $\leq 105 \mathrm{mg} /$ day) and a significantly reduced risk for lower doses of fluoxetine (0.72, 0.56 to 0.91 , for doses $\leq 20 \mathrm{mg} /$ day). Even for doses of citalopram of $40 \mathrm{mg} /$ day or greater, we saw no significantly increased risk (adjusted hazard ratio 1.11, 


\section{Table 2 | Unadjusted and adjusted hazard ratios for arrhythmia by antidepressant class, dose, and duration over 5 years' follow-up}

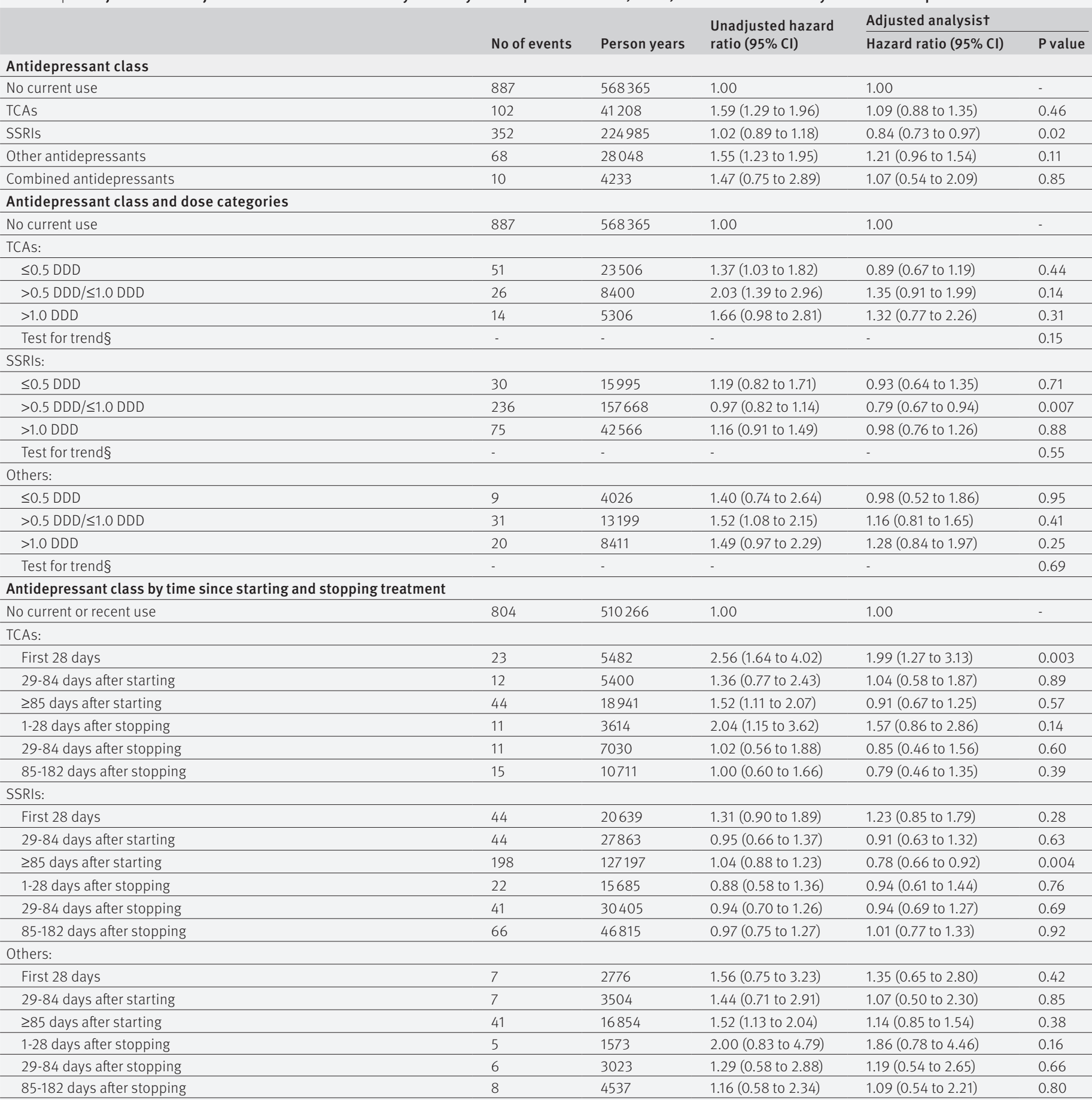

DDD=defined daily dose; SSRI=selective serotonin reuptake inhibitor; TCA=tricyclic and related antidepressant.

*Based on numbers in adjusted analysis.

TAdjusted for age, sex, year of diagnosis of depression, severity of depression, deprivation, smoking status, alcohol intake, ethnic group (white/not recorded or non-white), coronary heart disease, diabetes, hypertension, cancer, epilepsy/seizures, hypothyroidism, osteoarthritis, asthma/chronic obstructive pulmonary disease, stroke/transient ischaemic attack, rheumatoid arthritis, osteoporosis, liver disease, renal disease, obsessive-compulsive disorder, statins, non-steroidal anti-inflammatory drugs, aspirin, antihypertensives, anticonvulsants, hypnotics/ anxiolytics, oral contraceptives, hormone replacement therapy, antipsychotics, bisphosphonates, anticoagulants. ‡Daily doses could not be evaluated for some prescriptions.

$\S$ Test for trend uses continuous values of dose.

0.72 to 1.71$)$, although the number of events was small ( $\mathrm{n}=28$ ) (supplementary table C).

Adjusted hazard ratios were similar when patients who had not received any prescriptions for antidepressants during follow-up were removed from the analysis (supplementary table D) and when the entire follow-up period was used (supplementary table E), although more associations were significant owing to larger numbers. When we used just the first year of follow-up (table 4), results were similar to the five year analysis, although the hazard ratio for combined antidepressant use was higher (adjusted hazard ratio 


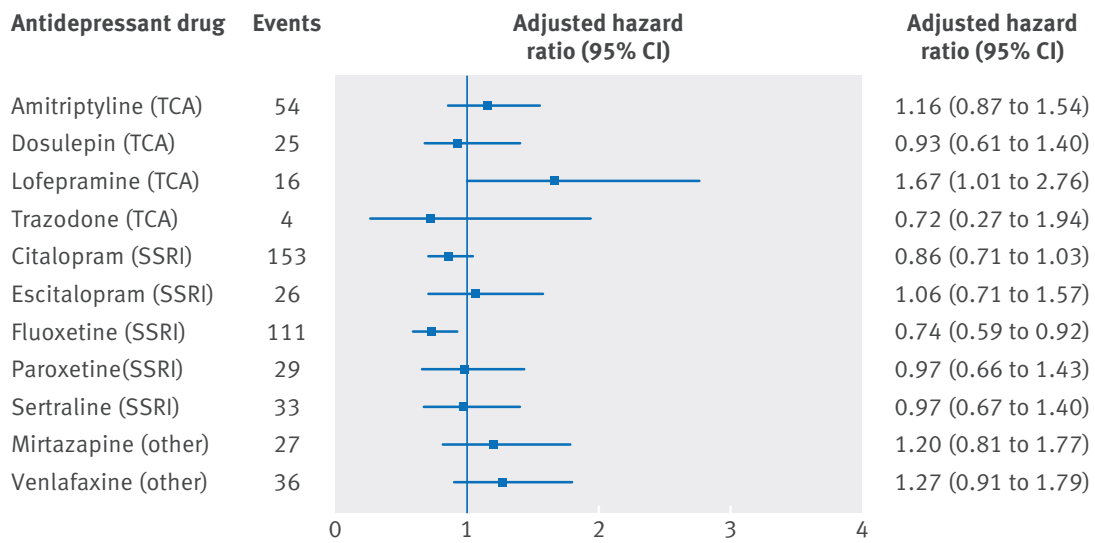

Fig 1 | Adjusted hazard ratios (compared with periods of non-use of antidepressants) for arrhythmia for individual antidepressant drugs over 5 years' follow-up. SSRI=selective serotonin reuptake inhibitor; TCA=tricyclic and related antidepressant

3.45, 1.24 to 9.57; $\mathrm{P}=0.017)$ and the association with fluoxetine was no longer statistically significant $(0.79$, 0.55 to $1.13 ; \mathrm{P}=0.19$ ). We found no indication of non-proportional hazards for the arrhythmia outcome; separate results for years 0-1, 1-3, and 3-5 of follow-up are shown in supplementary tables $\mathrm{F}$ and $\mathrm{G}$.

\section{Associations with myocardial infarction}

At baseline, 1790 patients had a previous diagnosis of myocardial infarction recorded. We excluded these patients from analysis of the myocardial infarction outcome, along with the patients who received monoamine oxidase inhibitors, leaving 237017 patients in the analysis cohort. During the first five years of follow-up, 772 new diagnoses of myocardial infarction were made, giving an incidence rate of 8.6 per 10000 person years (16.2 per 10000 in men and 3.9 per 10000 in women).

We found no significant association between antidepressant class and myocardial infarction over five years in the adjusted analysis (table 5) and no significant trends with dose. No clear pattern in risk according to different periods of time after starting or stopping antidepressant drugs was apparent, although rates were increased from 28 days after stopping tricyclic and related antidepressants.

Table 3 | Unadjusted and adjusted hazard ratios for arrhythmia by individual drug categorised according to dose for 5 years' follow-up*

\begin{tabular}{|c|c|c|c|c|c|}
\hline \multirow[b]{2}{*}{ Antidepressant drug } & \multirow{2}{*}{$\begin{array}{l}\text { No of } \\
\text { eventst }\end{array}$} & \multirow{2}{*}{$\begin{array}{l}\text { Person } \\
\text { yearst }\end{array}$} & \multirow{2}{*}{$\begin{array}{l}\text { Unadjusted hazard } \\
\text { ratio }(95 \% \mathrm{Cl})\end{array}$} & \multicolumn{2}{|l|}{ Adjusted analysis $¥$} \\
\hline & & & & Hazard ratio $(95 \% \mathrm{Cl})$ & Pvalue \\
\hline No current use & 887 & 568365 & 1.00 & 1.00 & - \\
\hline \multicolumn{6}{|c|}{ Tricyclic and related antidepressants } \\
\hline Amitriptyline: $\leq 1 \mathrm{DDD}$ & 41 & 16040 & - & - & - \\
\hline Amitriptyline: >1 DDD & 4 & 1442 & - & - & - \\
\hline Dosulepin: $\leq 1$ DDD & 23 & 10967 & - & - & - \\
\hline Dosulepin: >1 DDD & 1 & 205 & - & - & - \\
\hline Lofepramine: $\leq 1 \mathrm{DDD}$ & 8 & 961 & $5.19(2.55$ to 10.54$)$ & 3.89 (1.92 to 7.90$)$ & $<0.001$ \\
\hline Lofepramine: >1 DDD & 8 & 3394 & 1.49 (0.74 to 2.99$)$ & $1.17(0.58$ to 2.39$)$ & 0.66 \\
\hline Trazodone: $\leq 1$ DDD & 2 & 2139 & - & - & - \\
\hline Trazodone: >1 DDD & 1 & 19 & - & - & - \\
\hline \multicolumn{6}{|c|}{ Selective serotonin reuptake inhibitors } \\
\hline Citalopram: $\leq 1$ DDD & 115 & 72340 & 1.04 (0.85 to 1.28$)$ & 0.82 (0.66 to 1.01$)$ & 0.06 \\
\hline Citalopram: >1 DDD & 34 & 17854 & 1.27 (0.88 to 1.83$)$ & $1.08(0.74$ to 1.57$)$ & 0.70 \\
\hline Escitalopram: $\leq 1 \mathrm{DDD}$ & 18 & 9068 & 1.31 (0.81 to 2.12$)$ & 1.04 (0.63 to 1.72$)$ & 0.88 \\
\hline Escitalopram: >1 DDD & 7 & 3758 & 1.35 (0.69 to 2.64$)$ & $1.06(0.52$ to 2.16$)$ & 0.88 \\
\hline Fluoxetine: $\leq 1$ DDD & 91 & 68345 & 0.84 (0.66 to 1.07$)$ & 0.72 (0.56 to 0.91$)$ & 0.007 \\
\hline Fluoxetine: >1 DDD & 16 & 11072 & 0.92 (0.56 to 1.53$)$ & 0.78 (0.48 to 1.27$)$ & 0.32 \\
\hline Paroxetine: $\leq 1$ DDD & 19 & 12216 & 0.98 (0.62 to 1.57 ) & 0.84 (0.53 to 1.34$)$ & 0.46 \\
\hline Paroxetine: >1 DDD & 9 & 3398 & $1.72(0.90$ to 3.27$)$ & $1.47(0.77$ to 2.84$)$ & 0.25 \\
\hline Sertraline: $\leq 1$ DDD & 23 & 11539 & 1.31 (0.86 to 2.01 ) & 1.09 (0.70 to 1.68$)$ & 0.71 \\
\hline Sertraline: >1 DDD & 9 & 6448 & 0.89 (0.47 to 1.70$)$ & 0.78 (0.41 to 1.49 ) & 0.45 \\
\hline \multicolumn{6}{|l|}{ Others } \\
\hline Mirtazapine: $\leq 1$ DDD & 20 & 7533 & $1.74(1.13$ to 2.70$)$ & $1.17(0.75$ to 1.84$)$ & 0.49 \\
\hline Mirtazapine: >1 DDD & 6 & 1933 & 1.94 (0.89 to 4.23) & 1.48 (0.67 to 3.26$)$ & 0.33 \\
\hline Venlafaxine: $\leq 1 \mathrm{DDD}$ & 18 & 8432 & 1.35 (0.86 to 2.12 ) & $1.14(0.72$ to 1.81$)$ & 0.57 \\
\hline Venlafaxine: >1 DDD & 14 & 6369 & 1.38 (0.82 to 2.32$)$ & 1.24 (0.74 to 2.08$)$ & 0.42 \\
\hline
\end{tabular}

$\mathrm{DDD}=$ defined daily dose.

DDD values are amitriptyline $75 \mathrm{mg} /$ day; dosulepin $150 \mathrm{mg}$ /day; lofepramine $105 \mathrm{mg} /$ day; trazodone $300 \mathrm{mg}$ /day; citalopram $20 \mathrm{mg} /$ day; escitalopram

$10 \mathrm{mg} /$ day; fluoxetine $20 \mathrm{mg} /$ day; paroxetine $20 \mathrm{mg} /$ day; sertraline $50 \mathrm{mg} /$ day; mirtazapine $30 \mathrm{mg} /$ day; venlafaxine $100 \mathrm{mg} /$ day.

*Results only shown for drugs for which $\geq 5$ events were recorded in both dose categories.

tBased on numbers in adjusted analysis.

¥Adjusted for age, sex, year of diagnosis of depression, severity of depression, deprivation, smoking status, alcohol intake, ethnic group (white/not recorded or non-white), coronary heart disease, diabetes, hypertension, cancer, epilepsy/seizures, hypothyroidism, osteoarthritis, asthma/chronic obstructive pulmonary disease, stroke/transient ischaemic attack, rheumatoid arthritis, osteoporosis, liver disease, renal disease, obsessive compulsive disorder, statins, non-steroidal anti-inflammatory drugs, aspirin, antihypertensives, anticonvulsants, hypnotics/anxiolytics, oral contraceptives, hormone replacement therapy, antipsychotics, bisphosphonates, anticoagulants. 
Table 4 | Adjusted hazard ratios for arrhythmia, myocardial infarction, and stroke or transient ischaemic attack by antidepressant class, dose, and individual drug over first year of follow-up

\begin{tabular}{|c|c|c|c|c|c|c|c|c|c|}
\hline & \multicolumn{3}{|c|}{ Arrhythmia } & \multicolumn{3}{|c|}{ Myocardial infarction } & \multicolumn{3}{|c|}{ Stroke/TIA } \\
\hline & $\begin{array}{l}\text { No of } \\
\text { events }\end{array}$ & $\begin{array}{l}\text { Adjusted hazard } \\
\text { ratiot }(95 \% \mathrm{Cl})\end{array}$ & Pvalue & $\begin{array}{l}\text { No of } \\
\text { events }\end{array}$ & $\begin{array}{l}\text { Adjusted hazard } \\
\text { ratiot }(95 \% \mathrm{Cl})\end{array}$ & Pvalue & $\begin{array}{l}\text { No of } \\
\text { events }\end{array}$ & $\begin{array}{l}\text { Adjusted hazard } \\
\text { ratiot }(95 \% \mathrm{Cl})\end{array}$ & $P$ value \\
\hline \multicolumn{10}{|l|}{ Antidepressant class } \\
\hline No current use & 127 & 1.00 & - & 90 & 1.00 & - & 113 & 1.00 & - \\
\hline TCAs & 39 & $1.16(0.81$ to 1.67$)$ & 0.42 & 25 & 1.09 (0.72 to 1.66$)$ & 0.68 & 33 & $1.01(0.69$ to 1.49$)$ & 0.94 \\
\hline SSRIS & 141 & 0.86 (0.66 to 1.11$)$ & 0.24 & 63 & 0.58 (0.42 to 0.79$)$ & 0.001 & 118 & 0.83 (0.63 to 1.09$)$ & 0.18 \\
\hline Other antidepressants & 20 & 1.33 (0.84 to 2.12$)$ & 0.23 & 9 & 0.81 (0.42 to 1.58$)$ & 0.54 & 16 & 1.15 (0.69 to 1.90$)$ & 0.59 \\
\hline Combined antidepressants & 5 & $3.45(1.24$ to 9.57$)$ & 0.02 & 2 & $1.68(0.43$ to 6.65$)$ & 0.46 & 1 & 0.69 (0.10 to 4.96$)$ & 0.72 \\
\hline \multicolumn{10}{|c|}{ Antidepressant class and dose categories } \\
\hline No current use & 127 & 1.00 & - & 90 & 1.00 & - & 113 & 1.00 & - \\
\hline \multicolumn{10}{|l|}{ TCAs: } \\
\hline$\leq 0.5 \mathrm{DDD}$ & 21 & 0.98 (0.62 to 1.55$)$ & 0.92 & 12 & 0.86 (0.47 to 1.56$)$ & 0.62 & 18 & 0.87 (0.54 to 1.41$)$ & 0.58 \\
\hline$>0.5 \mathrm{DDD} / \leq 1.0 \mathrm{DDD}$ & 10 & $1.76(0.92$ to 3.35$)$ & 0.09 & 4 & 0.93 (0.35 to 2.50$)$ & 0.89 & 8 & 1.36 (0.66 to 2.78$)$ & 0.41 \\
\hline$>1.0 \mathrm{DDD}$ & 4 & $1.22(0.46$ to 3.24$)$ & 0.69 & 3 & $1.29(0.41$ to 4.04$)$ & 0.66 & 4 & $1.26(0.47$ to 3.38$)$ & 0.65 \\
\hline Test for trend $\neq$ & - & - & 0.83 & - & - & 0.47 & - & - & 0.23 \\
\hline \multicolumn{10}{|l|}{ SSRIS: } \\
\hline$\leq 0.5 \mathrm{DDD}$ & 11 & 0.95 (0.52 to 1.72$)$ & 0.85 & 5 & 0.76 (0.30 to 1.92$)$ & 0.56 & 7 & $0.73(0.34$ to 1.56$)$ & 0.42 \\
\hline$>0.5 \mathrm{DDD} / \leq 1.0 \mathrm{DDD}$ & 105 & 0.81 (0.62 to 1.08 ) & 0.15 & 43 & 0.52 (0.37 to 0.73$)$ & $<0.001$ & 90 & 0.81 (0.61 to 1.09 ) & 0.16 \\
\hline$>1.0 \mathrm{DDD}$ & 21 & $1.07(0.65$ to 1.76$)$ & 0.79 & 11 & 0.75 (0.41 to 1.36$)$ & 0.34 & 17 & 0.99 (0.59 to 1.67$)$ & 0.98 \\
\hline Test for trend‡ & - & - & 0.57 & - & - & 0.42 & - & - & 0.47 \\
\hline \multicolumn{10}{|l|}{ Others: } \\
\hline$\leq 0.5 \mathrm{DDD}$ & 3 & 1.06 (0.34 to 3.32$)$ & 0.93 & 2 & 0.95 (0.23 to 3.96$)$ & 0.95 & 4 & $1.58(0.57$ to 4.35$)$ & 0.38 \\
\hline$>0.5 \mathrm{DDD} / \leq 1.0 \mathrm{DDD}$ & 13 & 1.65 (0.91 to 2.98) & 0.10 & 3 & 0.53 (0.17 to 1.60$)$ & 0.26 & 7 & 0.95 (0.45 to 1.98$)$ & 0.88 \\
\hline$>1.0 \mathrm{DDD}$ & 2 & 0.80 (0.20 to 3.20$)$ & 0.76 & 2 & $1.04(0.26$ to 4.17$)$ & 0.95 & 4 & 1.76 (0.66 to 4.73$)$ & 0.26 \\
\hline Test for trendf & - & - & 0.51 & - & - & 0.40 & - & - & 0.72 \\
\hline \multicolumn{10}{|l|}{ Antidepressant drug } \\
\hline No current use & 130 & 1.00 & & 90 & 1.00 & & 113 & 1.00 & \\
\hline \multicolumn{10}{|l|}{ TCAs: } \\
\hline Amitriptyline & 18 & 1.15 (0.69 to 1.94$)$ & 0.59 & 8 & 0.75 (0.37 to 1.55$)$ & 0.44 & 15 & 1.00 (0.59 to 1.70$)$ & 1.00 \\
\hline Dosulepin & 8 & 0.73 (0.35 to 1.50$)$ & 0.39 & 8 & 1.07 (0.53 to 2.18$)$ & 0.85 & 12 & 1.12 (0.63 to 1.98$)$ & 0.70 \\
\hline Lofepramine & 8 & 2.13 (1.05 to 4.33$)$ & 0.04 & 8 & 3.07 (1.50 to 6.26) & 0.002 & 4 & 1.15 (0.43 to 3.11$)$ & 0.78 \\
\hline Trazodone & 3 & $1.72(0.53$ to 5.56$)$ & 0.36 & 1 & 0.73 (0.10 to 5.19$)$ & 0.76 & 1 & 0.56 (0.08 to 3.72$)$ & 0.55 \\
\hline \multicolumn{10}{|l|}{ SSRIS: } \\
\hline Citalopram & 56 & 0.79 (0.57 to 1.10$)$ & 0.17 & 27 & 0.59 (0.39 to 0.91$)$ & 0.017 & 43 & $0.73(0.51$ to 1.05$)$ & 0.09 \\
\hline Escitalopram & 9 & 1.01 (0.47 to 2.16$)$ & 0.99 & 4 & 0.67 (0.25 to 1.82$)$ & 0.43 & 5 & 0.63 (0.26 to 1.53$)$ & 0.31 \\
\hline Fluoxetine & 48 & 0.79 (0.55 to 1.13 ) & 0.19 & 18 & 0.44 (0.27 to 0.72$)$ & 0.001 & 56 & $1.06(0.76$ to 1.50$)$ & 0.72 \\
\hline Paroxetine & 13 & 1.10 (0.61 to 1.99$)$ & 0.74 & 3 & 0.38 (0.12 to 1.22$)$ & 0.10 & 7 & 0.63 (0.28 to 1.38$)$ & 0.25 \\
\hline Sertraline & 15 & 1.21 (0.71 to 2.07$)$ & 0.48 & 10 & 1.18 (0.64 to 2.20$)$ & 0.59 & 7 & 0.63 (0.30 to 1.35$)$ & 0.24 \\
\hline \multicolumn{10}{|l|}{ Others: } \\
\hline Mirtazapine & 8 & 1.20 (0.57 to 2.53) & 0.62 & 5 & 0.91 (0.37 to 2.24) & 0.84 & 12 & 1.85 (1.01 to 3.37) & 0.04 \\
\hline Venlafaxine & 11 & 1.64 (0.88 to 3.08$)$ & 0.12 & 4 & 0.89 (0.33 to 2.39 ) & 0.81 & 3 & 0.51 (0.16 to 1.57$)$ & 0.24 \\
\hline All other antidepressants & 3 & 0.90 (0.30 to 2.69$)$ & 0.85 & 1 & 0.46 (0.06 to 3.35$)$ & 0.44 & 2 & 0.64 (0.15 to 2.63$)$ & 0.53 \\
\hline Combined antidepressants & 5 & 3.44 (1.24 to 9.55) & 0.02 & 2 & $1.68(0.43$ to 6.64$)$ & 0.46 & 1 & 0.70 (0.10 to 4.97$)$ & 0.72 \\
\hline $\begin{array}{l}\text { SSRI=selective serotonin reupt } \\
\text { *Based on numbers in adjusted } \\
\text { tAdjusted for age, sex, year of c } \\
\text { disease, diabetes, hypertensior } \\
\text { stroke/TIA outcome), rheumato } \\
\text { anticonvulsants, hypnotics/anx }\end{array}$ & $\begin{array}{l}\text { =tricyclic } \\
\text { ssion, ses }\end{array}$ & $\begin{array}{l}\text { d related antidepressa } \\
\text { ity of depression, depr }\end{array}$ & $T \mid A=\operatorname{tra}$ & nt ischa & ic attack. & oidal ant & flamm & inon-white), coronary & $\begin{array}{l}\text { eart } \\
\text { the } \\
\text { rtensives, }\end{array}$ \\
\hline
\end{tabular}

We found no significant associations (at $\mathrm{P}<0.01$ ) for individual drugs in the adjusted analyses (fig 2) and no significant difference between the five selective serotonin reuptake inhibitors $(\mathrm{P}=0.27)$ or the four tricyclic and related antidepressants $(\mathrm{P}=0.26)$, although fluoxetine had an adjusted hazard ratio of 0.73 (0.54 to 0.98; $\mathrm{P}=0.04$ ) and lofepramine had an adjusted hazard ratio of 2.02 ( 1.14 to 3.59; $\mathrm{P}=0.02$ ), both compared with periods of no antidepressant treatment.
Adjusted hazard ratios were similar when patients who had not received any antidepressant prescriptions during follow-up were removed from the analysis (supplementary table $\mathrm{H}$ ) and when the entire follow-up period was used (supplementary table I). We saw some indication that hazard rates were not proportional over the five years of follow-up, and some differences in the hazard ratios were apparent when the analysis was restricted to the first year of follow-up 
Table 5 | Unadjusted and adjusted hazard ratios for myocardial infarction by antidepressant class, dose, and duration over 5 years' follow-up

\begin{tabular}{|c|c|c|c|c|c|}
\hline & \multirow{2}{*}{$\begin{array}{l}\text { No of } \\
\text { events* }\end{array}$} & \multirow{2}{*}{$\begin{array}{l}\text { Person } \\
\text { years* }\end{array}$} & \multirow{2}{*}{$\begin{array}{l}\text { Unadjusted hazard } \\
\text { ratio }(95 \% \mathrm{Cl})\end{array}$} & \multicolumn{2}{|l|}{ Adjusted analysist } \\
\hline & & & & Hazard ratio $(95 \% \mathrm{Cl})$ & Pvalue \\
\hline \multicolumn{6}{|l|}{ Antidepressant class } \\
\hline No current use & 469 & 570843 & 1.00 & 1.00 & \\
\hline TCAs & 63 & 41295 & 1.83 (1.44 to 2.33$)$ & 1.20 (0.94 to 1.52$)$ & 0.14 \\
\hline SSRIS & 182 & 225863 & 1.02 (0.86 to 1.22$)$ & 0.85 (0.71 to 1.00$)$ & 0.06 \\
\hline Other antidepressants & 33 & 28144 & 1.39 (0.98 to 1.98$)$ & 1.00 (0.70 to 1.42$)$ & 0.98 \\
\hline Combined antidepressants & 3 & 4224 & 0.84 (0.27 to 2.59$)$ & 0.57 (0.18 to 1.75$)$ & 0.32 \\
\hline \multicolumn{6}{|c|}{ Antidepressant class and dose categories } \\
\hline No current use & 469 & 570843 & 1.00 & 1.00 & \\
\hline \multicolumn{6}{|l|}{ TCAs: } \\
\hline$\leq 0.5 \mathrm{DDD}$ & 31 & 23555 & 1.59 (1.11 to 2.26$)$ & $1.02(0.72$ to 1.45$)$ & 0.89 \\
\hline$>0.5 \mathrm{DDD} / \leq 1.0 \mathrm{DDD}$ & 15 & 8412 & 2.15 (1.31 to 3.53$)$ & 1.29 (0.78 to 2.13$)$ & 0.32 \\
\hline$>1.0 \mathrm{DDD}$ & 10 & 5318 & $2.24(1.21$ to 4.16$)$ & 1.59 (0.86 to 2.97$)$ & 0.14 \\
\hline Test for trend§ & - & - & - & - & 0.35 \\
\hline \multicolumn{6}{|l|}{ SSRIS: } \\
\hline$\leq 0.5 \mathrm{DDD}$ & 14 & 16132 & $1.12(0.68$ to 1.86$)$ & 0.97 (0.57 to 1.63$)$ & 0.90 \\
\hline$>0.5 \mathrm{DDD} / \leq 1.0 \mathrm{DDD}$ & 110 & 158252 & $0.89(0.72$ to 1.11$)$ & 0.73 (0.59 to 0.91$)$ & 0.005 \\
\hline$>1.0 \mathrm{DDD}$ & 50 & 42683 & 1.46 (1.11 to 1.92$)$ & 1.16 (0.88 to 1.54$)$ & 0.30 \\
\hline Test for trend§ & - & - & - & - & 0.03 \\
\hline \multicolumn{6}{|l|}{ Others: } \\
\hline$\leq 0.5 \mathrm{DDD}$ & 9 & 4041 & 2.65 (1.38 to 5.10$)$ & 1.80 (0.94 to 3.45$)$ & 0.08 \\
\hline$>0.5 \mathrm{DDD} / \leq 1.0 \mathrm{DDD}$ & 8 & 13236 & 0.72 (0.36 to 1.43$)$ & 0.51 (0.26 to 1.02$)$ & 0.06 \\
\hline$>1.0 \mathrm{DDD}$ & 11 & 8440 & 1.54 (0.86 to 2.78$)$ & 1.11 (0.61 to 2.00$)$ & 0.74 \\
\hline Test for trend§ & - & - & - & - & 0.79 \\
\hline \multicolumn{6}{|c|}{ Antidepressant class by time since starting and stopping treatment } \\
\hline No current or recent use & 416 & 512509 & 1.00 & 1.00 & \\
\hline \multicolumn{6}{|l|}{ TCAs: } \\
\hline First 28 days & 6 & 5499 & 1.08 (0.48 to 2.44$)$ & 0.83 (0.37 to 1.86$)$ & 0.65 \\
\hline 29-84 days after starting & 5 & 5414 & 1.05 (0.44 to 2.51$)$ & 0.77 (0.32 to 1.83$)$ & 0.55 \\
\hline$\geq 85$ days after starting & 33 & 18957 & $2.17(1.56$ to 3.00$)$ & 1.23 (0.89 to 1.71$)$ & 0.21 \\
\hline 1-28 days after stopping & 5 & 3627 & 1.60 (0.66 to 3.86$)$ & 1.30 (0.54 to 3.12$)$ & 0.56 \\
\hline 29-84 days after stopping & 13 & 7056 & $2.32(1.32$ to 4.06$)$ & 1.85 (1.05 to 3.23$)$ & 0.03 \\
\hline 85-182 days after stopping & 20 & 10753 & 2.36 (1.47 to 3.78$)$ & 1.89 (1.18 to 3.02$)$ & 0.008 \\
\hline \multicolumn{6}{|l|}{ SSRIS: } \\
\hline First 28 days & 14 & 20710 & $0.66(0.35$ to 1.25$)$ & 0.63 (0.32 to 1.22$)$ & 0.17 \\
\hline 29-84 days after starting & 14 & 27967 & 0.59 (0.34 to 1.02$)$ & 0.56 (0.31 to 0.99$)$ & 0.05 \\
\hline$\geq 85$ days after starting & 109 & 127711 & $1.12(0.91$ to 1.38$)$ & 0.84 (0.68 to 1.03$)$ & 0.10 \\
\hline 1-28 days after stopping & 20 & 15744 & $1.64(1.04$ to 2.60$)$ & $1.66(1.05$ to 2.63$)$ & 0.03 \\
\hline 29-84 days after stopping & 22 & 30521 & 0.96 (0.61 to 1.49$)$ & 1.00 (0.64 to 1.58$)$ & 0.98 \\
\hline 85-182 days after stopping & 33 & 47004 & 0.95 (0.65 to 1.38$)$ & 0.99 (0.67 to 1.45$)$ & 0.95 \\
\hline \multicolumn{6}{|l|}{ Others: } \\
\hline First 28 days & 5 & 2788 & $1.91(0.76$ to 4.84$)$ & $1.52(0.60$ to 3.82$)$ & 0.37 \\
\hline 29-84 days after starting & 2 & 3514 & 0.67 (0.17 to 2.66$)$ & 0.53 (0.13 to 2.08$)$ & 0.36 \\
\hline$\geq 85$ days after starting & 20 & 16908 & $1.44(0.90$ to 2.29$)$ & 0.96 (0.60 to 1.53$)$ & 0.87 \\
\hline 1-28 days after stopping & 1 & 1580 & 0.75 (0.11 to 5.35) & 0.64 (0.09 to 4.54$)$ & 0.65 \\
\hline 29-84 days after stopping & 4 & 3036 & 1.64 (0.62 to 4.37$)$ & $1.38(0.52$ to 3.67$)$ & 0.52 \\
\hline 85-182 days after stopping & 5 & 4557 & 1.37 (0.56 to 3.33$)$ & $1.17(0.48$ to 2.85$)$ & 0.72 \\
\hline
\end{tabular}

DDD=defined daily dose; SSRI=selective serotonin reuptake inhibitor; TCA=tricyclic and related antidepressant.

*Based on numbers in adjusted analysis

†Adjusted for age, sex, year of diagnosis of depression, severity of depression, deprivation, smoking status, alcohol intake, ethnic group (white/not recorded or non-white), coronary heart disease, diabetes, hypertension, cancer, epilepsy/seizures, hypothyroidism, osteoarthritis, asthma/chronic obstructive pulmonary disease, stroke/transient ischaemic attack, rheumatoid arthritis, osteoporosis, liver disease, renal disease, obsessive-compulsive disorder, statins, non-steroidal anti-inflammatory drugs, aspirin, antihypertensives, anticonvulsants, hypnotics/ anxiolytics, oral contraceptives, hormone replacement therapy, antipsychotics, bisphosphonates, anticoagulants.

¥Daily doses could not be evaluated for some prescriptions.

$\S$ Test for trend uses continuous values of dose.

compared with values over five years. In this one year analysis (table 4), we found a significantly reduced risk for selective serotonin reuptake inhibitors compared with no use of antidepressants (adjusted hazard ratio 0.58 , 0.42 to $0.79 ; \mathrm{P}=0.001)$; although overall no significant difference (at $\mathrm{P}<0.01)$ existed between the five selective serotonin reuptake inhibitors $(\mathrm{P}=0.11)$ or the four tricyclic and related antidepressants $(\mathrm{P}=0.03)$, a significant reduction occurred with fluoxetine (adjusted hazard ratio $0.44,0.27$ to $0.72 ; \mathrm{P}=0.001$ ) and a significant increase with lofepramine $(3.07,1.50$ to 6.26; $\mathrm{P}=0.002$ ). We found no significant associations 


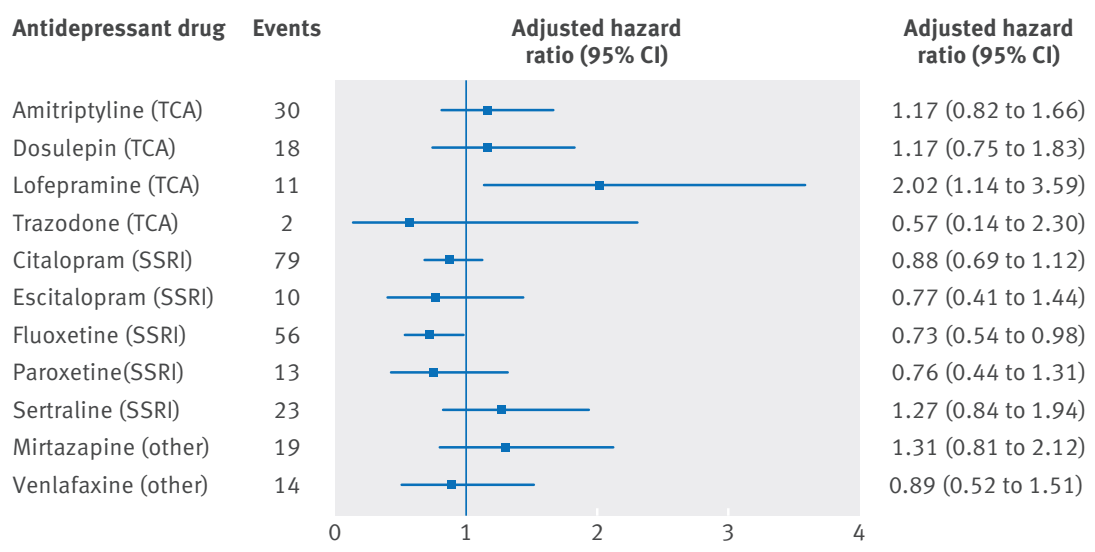

Fig 2 | Adjusted hazard ratios (compared with periods of non-use of antidepressants) for myocardial infarction for individual antidepressant drugs over 5 years' follow-up. SSRI=selective serotonin reuptake inhibitor; TCA=tricyclic and related antidepressant

with selective serotonin reuptake inhibitors in years 1-3 and 3-5 of follow-up (supplementary table F) or with fluoxetine (supplementary table G).

\section{Associations with stroke/transient ischaemic attack}

At baseline, 1741 patients had a diagnosis of stroke or transient ischaemic attack recorded. These patients were excluded from analysis of the stroke/transient ischaemic attack outcome, along with the patients who received monoamine oxidase inhibitors, leaving 237067 patients in the analysis cohort. During the first five years of follow-up, 1106 new diagnoses of stroke or transient ischaemic attack were made, giving an incidence rate of 12.3 per 10000 person years (17.3 per 10000 in men and 9.3 per 10000 in women).

We found no significant associations between antidepressant class and stroke/transient ischaemic attack over five years and no significant trends (at $\mathrm{P}<0.01)$ with dose (table 6). A significant increase in risk occurred during the first 28 days after starting other antidepressants (adjusted hazard ratio 2.72, 1.45 to 5.08; $\mathrm{P}=0.002$ ) and from 85 to 182 days after stopping tricyclic and related antidepressants (1.82, 1.21 to $2.74 ; \mathrm{P}=0.004)$. Rates were also increased in the first 84 days after starting tricyclic and related antidepressants, although not significantly (at $\mathrm{P}<0.01)$.

In the adjusted analysis of individual antidepressant drugs, we found no significant associations for any of the drugs (fig 3).

Adjusted hazard ratios were similar when patients who had not received any prescriptions for antidepressants during follow-up were removed (supplementary table J) and when the entire follow-up period was used (supplementary table K), but they tended to be lower when just the first year of follow-up was used in the analysis (table 4). We saw some indication that hazard rates were not proportional over the five years of followup, with higher hazard ratios in the later periods of follow-up for tricyclic and related antidepressants and selective serotonin reuptake inhibitors (supplementary tables $F$ and $G$ ).

\section{Additional analyses}

The results of analyses including confounding variables in blocks are shown in supplementary tables $\mathrm{L}$ to $\mathrm{N}$, showing that adjustment for age, sex, deprivation, ethnic group, and year of diagnosis had a marked effect on hazard ratios, but additional adjustment for further blocks of variables had a relatively small effect. Results were similar to those of our main models which used robust standard errors when the Cox models were stratified by general practice.

\section{Absolute risks}

Table 7 shows absolute risks of the three outcomes over one year by antidepressant class and for the individual drugs. Absolute risks of arrhythmia and myocardial infarction were highest for lofepramine (30 per 10000 and 31 per 10000, respectively), and for stroke/transient ischaemic attack they were highest for mirtazapine (24 per 10000). However, the 95\% confidence intervals for these values were wide and mainly overlapped with the other drugs.

\section{Discussion}

The main findings of this large population based cohort study were that selective serotonin reuptake inhibitors were not associated with an increased risk of arrhythmia, myocardial infarction, or stroke or transient ischaemic attack in a general population cohort of people with depression aged 20 to 64 and that risk of arrhythmia was not significantly increased in patients treated with citalopram even at high doses ( $40 \mathrm{mg} /$ day and over), although numbers in this category were relatively small. We found some evidence that selective serotonin reuptake inhibitors were associated with a reduced risk of arrhythmia and myocardial infarction. Fluoxetine was associated with the lowest risks of these two outcomes, but overall no significant differences were seen between the selective serotonin reuptake inhibitors. The risk of arrhythmia was significantly increased in the first four weeks of starting tricyclic and related antidepressants, and the tricyclic drug lofepramine was associated with a significantly increased risk of myocardial infarction in the first year of follow-up.

\section{Strengths and limitations of study}

This study included a large representative sample of people aged 20 to 64 diagnosed as having depression in the general UK population and had a long follow-up period. All eligible patients were included, so no bias due to non-response was present, and no recall bias occurred because data on prescriptions and confounding variables were recorded prospectively before the outcomes occurred. We reduced indication bias by restricting our cohort to include only patients with a diagnosis of depression, as depression itself is an established risk factor for cardiovascular outcomes, ${ }^{3031}$ and separating the effects of antidepressant treatment from those of depression would otherwise be difficult. This means that our findings can be generalised only to people diagnosed as having depression. 
Table 6 | Unadjusted and adjusted hazard ratios for stroke or transient ischaemic attack by antidepressant class, dose, and duration over 5 years' follow-up.

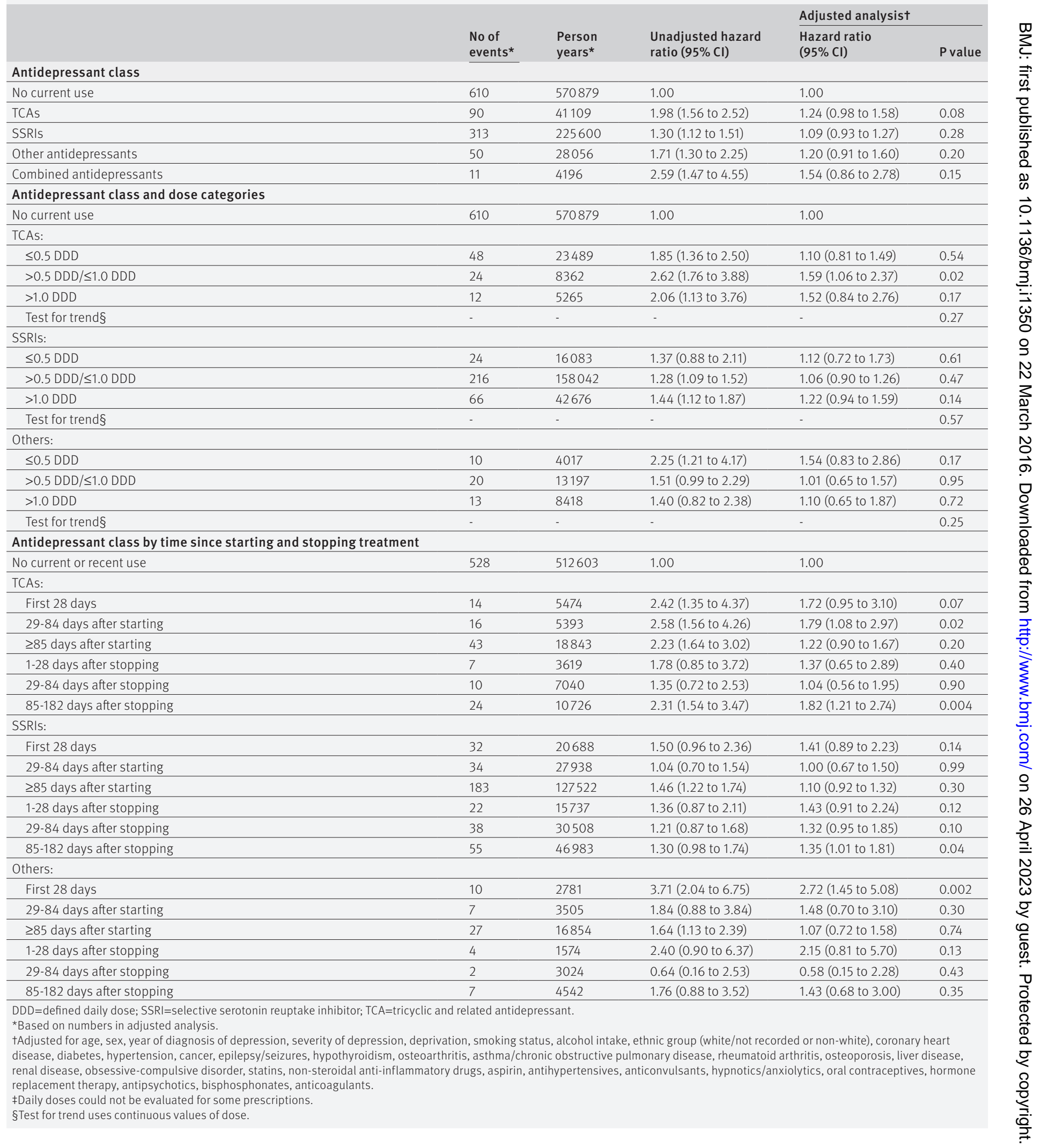

Some bias may remain in comparisons between antidepressant drugs if the selection of a particular antidepressant was influenced by risk factors for the outcome, but we accounted for a large number of potential confounding variables in the analysis to reduce differences between comparison groups. The increased risk for lofepramine in some analyses may nevertheless reflect preferential selection of this drug in patients considered to be more prone to arrhythmias or heart disease, as this drug is viewed as being safer in overdose and 


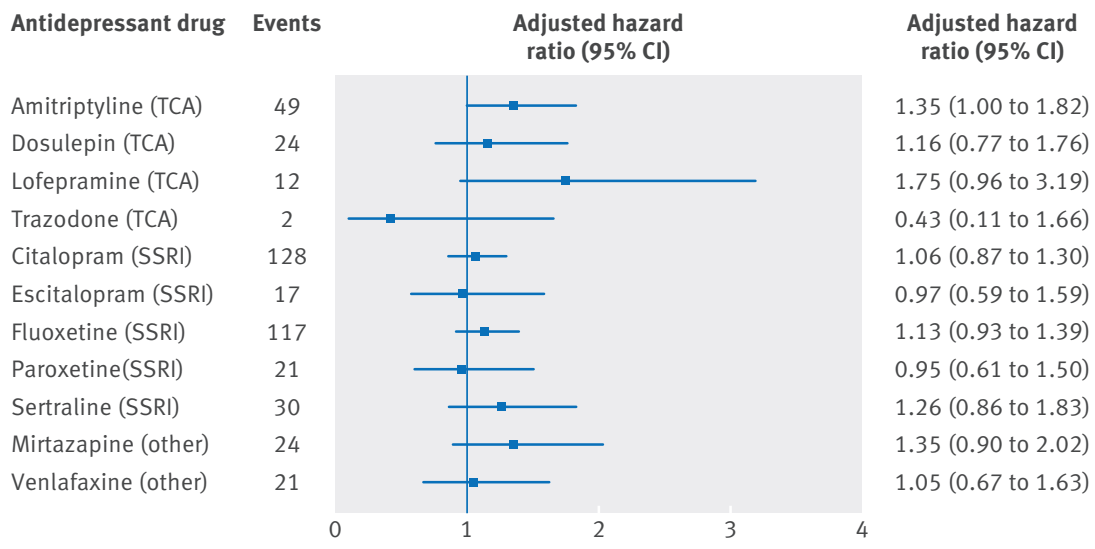

Fig 3 | Adjusted hazard ratios (compared with periods of non-use of antidepressants) for stroke or transient ischaemic attack for individual antidepressant drugs over 5 years' follow-up. SSRI=selective serotonin reuptake inhibitor; TCA=tricyclic and related antidepressant

less cardiotoxic than other tricyclic and related antidepressants. ${ }^{3233}$ The increased risk of arrhythmia for low doses of lofepramine but not higher doses supports this, whereby patients at highest risk are treated with lower doses, although numbers of events were small in both dose categories. However, in a comparison of baseline characteristics of patients who received prescriptions for different antidepressants, we saw no indication that lofepramine was prescribed more frequently than other tricyclic antidepressants to patients with cardiovascular risk factors. ${ }^{22}$ For example, among patients

\begin{tabular}{|c|c|c|c|}
\hline \multirow[b]{2}{*}{ Treatment } & \multicolumn{3}{|c|}{ Absolute risk per 10,000 over 1 year $(95 \% \mathrm{Cl})$} \\
\hline & Arrhythmia* & $\begin{array}{l}\text { Myocardial } \\
\text { infarctiont }\end{array}$ & Stroke/TIA \\
\hline No treatment & $14(11$ to 17$)$ & 10 (8 to 12$)$ & 13 (11 to 16$)$ \\
\hline \multicolumn{4}{|l|}{ Antidepressant class } \\
\hline TCAs & 16 (11 to 23$)$ & $11(7$ to 17$)$ & 13 (9 to 19) \\
\hline SSRIS & $12(9$ to 16$)$ & $6(4$ to 8$)$ & $11(8$ to 14$)$ \\
\hline Other antidepressants & 19 (12 to 30$)$ & 8 (4 to 16$)$ & 15 (9 to 25$)$ \\
\hline Combined antidepressants & $48(17$ to 133$)$ & $17(4$ to 66$)$ & $9(1$ to 64$)$ \\
\hline \multicolumn{4}{|l|}{ Antidepressant drug } \\
\hline \multicolumn{4}{|l|}{ TCAs: } \\
\hline Amitriptyline & 16 (10 to 27$)$ & $8(4$ to 16$)$ & 13 (8 to 22$)$ \\
\hline Dosulepin & $10(5$ to 21$)$ & $11(5$ to 22$)$ & 15 (8 to 26$)$ \\
\hline Lofepramine & $30(15$ to 60$)$ & 31 (15 to 62) & $15(6$ to 40$)$ \\
\hline Trazodone & 24 (7 to 78$)$ & $7(1$ to 52$)$ & 7 (1 to 48) \\
\hline \multicolumn{4}{|l|}{ SSRIS: } \\
\hline Citalopram & 11 (8 to 15$)$ & $6(4$ to 9$)$ & $10(7$ to 14$)$ \\
\hline Escitalopram & 14 (7 to 30$)$ & 7 (2 to 18$)$ & 8 (3 to 20) \\
\hline Fluoxetine & 11 (8 to 16) & $4(3$ to 7$)$ & $14(10$ to 19$)$ \\
\hline Paroxetine & 15 (9 to 28$)$ & $4(1$ to 12$)$ & 8 (4 to 18$)$ \\
\hline Sertraline & 17 (10 to 29$)$ & 12 (6 to 22$)$ & 8 (4 to 18$)$ \\
\hline \multicolumn{4}{|l|}{ Others: } \\
\hline Mirtazapine & 17 (8 to 35$)$ & 9 (4 to 22$)$ & $24(13$ to 44$)$ \\
\hline Venlafaxine & 23 (12 to 43$)$ & 9 (3 to 24) & 7 (2 to 20$)$ \\
\hline All other antidepressants & $13(4$ to 38$)$ & 5 (1 to 33) & 8 (2 to 34$)$ \\
\hline \multicolumn{4}{|c|}{$\begin{array}{l}\text { SSRI=selective serotonin reuptake inhibitor; TCA=tricyclic and related antidepressant; TIA=transient ischaemic } \\
\text { attack. } \\
\text { ^Absolute risks are adjusted for confounders listed in table } 2 . \\
\text { †Absolute risks are adjusted for confounders listed in table } 5 . \\
\text { †Absolute risks are adjusted for confounders listed in table } 6 .\end{array}$} \\
\hline
\end{tabular}

whose first antidepressant prescription was for lofepramine, $1.1 \%$ had coronary heart disease compared with $2.1 \%$ for amitriptyline, and $0.8 \%$ had a previous stroke recorded compared with $1.0 \%$ for amitriptyline. Similarly, we observed no indication that fluoxetine was prescribed more frequently than other selective serotonin reuptake inhibitors to younger patients or patients with fewer cardiovascular risk factors. For example, the mean age of patients when first treated with fluoxetine was 38.8 years, compared with 39.8 for citalopram and 38.3 for paroxetine, and the proportion of patients with hypertension when first treated with fluoxetine was $6.7 \%$, whereas for paroxetine it was $5.3 \% .^{22}$

Some residual confounding may still be present owing to variables that either were not recorded on the database, such as dietary factors and physical activity, or were not recorded in sufficient detail for their confounding effect to be completely removed by analysis. Although we adjusted for severity of depression, this was based on a basic classification of diagnostic Read codes for depression, as depression severity scores are not routinely recorded in general practice. Numbers of patients in the different non-white ethnic groups were small, so we combined these for inclusion in the analysis, which may contribute to residual confounding. Some misclassification of the antidepressant exposure variables will have occurred, as some patients may not have taken their prescribed antidepressant or may not have taken it at the prescribed dose. This misclassification could underestimate associations with drug use. Furthermore, although the cohort was large, the number of events was small for some of the antidepressant exposure categories. In particular, there were relatively few prescriptions for citalopram at doses of $40 \mathrm{mg} /$ day or more (19\% of citalopram prescriptions), and only 28 diagnoses of arrhythmia in this category, so the 95\% confidence interval for risk of arrhythmia with high doses of citalopram is wide, and increases in risk of up to $71 \%$ cannot be excluded.

The outcomes were not formally adjudicated in this study, but validation studies in other UK primary care databases have shown high levels of validity across a range of diseases, and we would expect levels of validity to be similar in QResearch. ${ }^{3435}$ For example, Khan reported high positive predictive values in validation studies of acute myocardial infarction and cerebrovascular disease. ${ }^{35}$ A study validating diagnostic codes for ventricular arrhythmia and sudden cardiac death reported a positive predictive value of $93 \% .{ }^{36}$ We included information from death certificates to identify additional patients with the outcomes, which will have increased ascertainment and reduced misclassification.

\section{Comparison with other studies}

Our results for arrhythmia are consistent with those of two other large cohort studies in finding no increased risk for citalopram, ${ }^{18} 19$ even at high doses, and our rates of arrhythmia are of the same order of magnitude. Our study adds new information on risks associated with other antidepressant drugs and on effects of 
duration of treatment. Our findings contrast to some extent with those of studies that have found QT interval prolongation in patients taking citalopram. ${ }^{14-16}$ One cross sectional study, ${ }^{15}$ which included 38397 patients aged 18 and over with an electrocardiogram recorded after prescription of antidepressant or methadone, found that QT prolongation was associated with dose for citalopram, escitalopram, and amitriptyline but not for other antidepressants examined. A study of psychiatric inpatients aged 18 and over found that most people with QT prolongation had two or more risk factors for QT prolongation, such as hypokalaemia, HIV infection, abnormal T wave morphology, and alcohol or drug use disorders, and that citalopram (including escitalopram) was significantly associated with QT prolongation after adjustment for these factors. ${ }^{16}$ This lack of coherence may reflect the smaller numbers of arrhythmia outcomes in the cohort studies when split by antidepressant drug and dose. Thus, power to detect an increased risk among higher antidepressant dose categories is low in comparison with studies that measure QT interval in adults receiving different doses of antidepressants and treat it as a continuous outcome variable in the analyses. ${ }^{1415}$ Torsades de pointes, which is the type of arrhythmia most closely related to QT interval prolongation, is extremely rare, so cohort studies (including ours) cannot rule out an association for this particular type of arrhythmia. Furthermore, a surrogate measure such as QT interval may not necessarily translate into an effect on a clinically important outcome such as arrhythmia. Our findings of an increased risk of arrhythmia in the first four weeks of starting a tricyclic antidepressant is consistent with several potential arrhythmias that can occur with tricyclic overdose in people with previously unsuspected cardiac abnormalities such as bundle branch block ${ }^{3738}$; our findings are important, as few studies have examined this for prescribed doses of tricyclic antidepressants.

In our previous study of antidepressants in people aged 65 and over with depression, ${ }^{10} 25$ we found a significantly increased risk of myocardial infarction with selective serotonin reuptake inhibitors but not with tricyclic or other antidepressants. Other observational studies have found similar results for selective serotonin reuptake inhibitors, ${ }^{39} 40$ whereas several have found no association ${ }^{11} 124142$ or a reduced risk ${ }^{134344}$; few studies have assessed risks for individual antidepressants. A meta-analysis of 16 observational studies concluded that use of neither selective serotonin reuptake inhibitors nor tricyclic antidepressants is associated with an increased risk of coronary heart disease, ${ }^{45}$ but only two studies were restricted to patients with depression. These contradictory findings are likely to be due to differences between studies, as they vary considerably in their sizes and inclusion criteria. Several studies either did not restrict their study sample to patients with depression or did not account for depression in the analysis and so are highly susceptible to indication bias because depression is a strong risk factor for cardiovascular disease $\mathrm{e}^{11-13}$; some studies are only in older or postmenopausal populations ${ }^{103942}$; and one was an interview based case-control study prone to recall bias. ${ }^{44}$ Why our results differ from those of our previous study in older people, which had a very similar study design, is unclear, ${ }^{10}$ but it could be due to the larger number of myocardial infarction events $(n=2350)$ in the older cohort or increased susceptibility to side effects in older people resulting from age related pharmacokinetic changes, ${ }^{46}$ or the high prevalence of multimorbidity and use of concomitant drugs in older people may result in interactions giving different patterns of risk with antidepressant use.

Observational studies of antidepressants and stroke have shown a more consistent pattern; several studies have found an increased risk of stroke with selective serotonin reuptake inhibitor use. ${ }^{104247-49}$ A systematic review and meta-analysis of 13 observational studies of selective serotonin reuptake inhibitors and stroke reported that selective serotonin reuptake inhibitors were associated with an increased risk of all types of stroke (overall adjusted odds ratio 1.40, 95\% confidence interval 1.09 to 1.80 ) and that the risk was still significantly increased when the analysis was restricted to the studies in which potential confounding by depression was considered. ${ }^{9}$ In a subgroup analysis by age group, the combined odds ratio for all types of stroke associated with selective serotonin reuptake inhibitor use was significant only in the four studies restricted to people aged at least 50 years (overall adjusted odds ratio 1.58, 1.06 to 2.36$),{ }^{10425051}$ and no significantly increased risk was seen in studies with no age restriction (overall adjusted odds ratio $1.13,0.91$ to 1.39 ). This concurs with our findings in this study of no association between selective serotonin reuptake inhibitors and stroke in people aged 20 to 64 and of an increased risk in our previous study in people aged 65 and over. ${ }^{10}$

\section{Clinical implications and future research}

Prescription of antidepressants is a complex process, involving balancing of risks and benefits for different antidepressants and doses, accounting for severity of depression, and considering patients' risk factors, comorbidities, and preferences. The results of this study in adults aged 20 to 64 are reassuring in light of recent concerns about citalopram and potential risk of arrhythmia; however, as only small numbers of patients were treated with high doses of citalopram, we cannot rule out the possibility of an increased risk. We suggest that high doses of citalopram should not be prescribed without a strong indication, particularly in patients with any risk factors for an increased QT interval. We also found no evidence that selective serotonin reuptake inhibitors are associated with an increased risk of myocardial infarction or stroke/transient ischaemic attack in this age group; they may even be associated with a reduced risk of myocardial infarction and arrhythmia, particularly for fluoxetine. The potential cardioprotective effects of selective serotonin reuptake inhibitors, particularly fluoxetine, warrant further investigation. 
The risk of arrhythmia was increased during the first 28 days of taking tricyclic and related antidepressants, and among the antidepressants studied lofepramine had the highest risks of arrhythmia, myocardial infarction, and stroke/transient ischaemic attack. This finding may reflect selective prescribing of lofepramine, as it is generally considered to be safer than other tricyclic and related antidepressants in overdose, but could also indicate increased risks when it is taken at doses typically prescribed in primary care. Further research using other designs such as the self controlled case series approach may help to elucidate this association.

\section{Conclusions}

This large observational study has found no evidence that selective serotonin reuptake inhibitors are associated with an increased risk of arrhythmia, myocardial infarction, or stroke/transient ischaemic attack in people with depression aged 20 to 64 , but some indication that they are associated with a reduced risk of myocardial infarction and arrhythmia, particularly for fluoxetine. Citalopram was not significantly associated with an increased risk of arrhythmia, even at higher doses, although the confidence interval was wide. These findings are reassuring in light of recent safety concerns about selective serotonin reuptake inhibitors.

We acknowledge the contribution of practices that contribute to the QResearch, as well as Egton Medical Information Systems (EMIS) and the University of Nottingham for expertise in establishing, developing and supporting the database. We acknowledge the Office of National Statistics for providing mortality data.

Contributors: $\mathrm{CC}, \mathrm{JH}-\mathrm{C}, \mathrm{RM}, \mathrm{AA}$, and MM contributed to the overall conception and design of the study. CC wrote the first draft of this manuscript. JH-C did the data extraction. TH and CC did the statistical analyses. All authors contributed to interpretation of results and drafting of this manuscript. All authors read and approved the final manuscript. CC is the guarantor.

Funding: The project was funded by the National Institute for Health Research (NIHR) School for Primary Care Research (project number 81). The funding body did not play a role in the study design, the writing of the manuscript, or the decision to submit the manuscript for publication. This paper presents independent research funded by the NIHR. The views expressed are those of the authors and not necessarily those of the NHS, the NIHR, or the Department of Health. RM's contribution to the study has been funded through the NIHR Collaboration for Leadership in Applied Health Research and Care East Midlands (CLAHRC EM).

Competing interests: All authors have completed the ICMJE uniform disclosure form at www.icmje.org/coi_disclosure.pdf (available on request from the corresponding author) and declare: financial support from NIHR for the submitted work; JH-C is director of QResearch, which is a not for profit venture between the University of Nottingham and EMIS (commercial supplier of GP clinical systems); no financial relationships with any organisations that might have an interest in the submitted work in the previous three years; no other relationships or activities that could appear to have influenced the submitted work.

Ethical approval: The project has been independently peer reviewed and accepted by the QResearch Scientific board and has been approved in accordance with the agreed procedure with the Trent Research Ethics Committee (reference number: MREC/03/4/021).

Transparency declaration: The lead author (the manuscript's guarantor) affirms that this manuscript is an honest, accurate, and transparent account of the study being reported; that no important aspects of the study have been omitted; and that any discrepancies from the study as planned (and, if relevant, registered) have been explained.

Data sharing: The patient level data from the QResearch are specifically licensed according to its governance framework. See www. qresearch.org for further details.
This is an Open Access article distributed in accordance with the terms of the Creative Commons Attribution (CC BY 3.0) license, which permits others to distribute, remix, adapt and build upon this work, for commercial use, provided the original work is properly cited. See: http://creativecommons.org/licenses/by/3.0/.

1 Hatcher S, Arroll B. Newer antidepressants for the treatment of depression in adults. BMJ 2012;344:d8300. doi:10.1136/bmj. d8300.

2 Jolly K, Langman MJS. Psychotropic medication: curing illness or creating problems?Heart 2009;95:1893-4. doi:10.1136/ hrt.2009.179127.

3 Olfson M, Marcus SC. National patterns in antidepressant medication treatment. Arch Gen Psychiatry 2009;66:848-56. doi:10.1001/ archgenpsychiatry.2009.81.

4 Lockhart P, Guthrie B. Trends in primary care antidepressant prescribing 1995-2007: a longitudinal population database analysis. BrJ Gen Pract 2011;61:e565-72. doi:10.3399/bjgp11X593848.

5 Stephenson CP, Karanges E, McGregor IS. Trends in the utilisation of psychotropic medications in Australia from 2000 to 2011. Aust N ZJ Psychiatry 2013;47:74-87. doi:10.1177/0004867412466595.

6 Pratt L, Brody D, Gu Q. Antidepressant use in persons aged 12 and over: United States, 2005-2008. NCHS data brief, no 76. National Center for Health Statistics, 2011.

7 Health and Social Care Information Centre. Prescription cost analysis, England 2013. 2014. http://www.hscic.gov.uk/catalogue/PUB13887.

8 Department of Health. Prescription cost analysis: England 2003. 2004. http://webarchive.nationalarchives.gov.uk/+/www.dh.gov.uk/ en/Publicationsandstatistics/Statistics/StatisticalWorkAreas/ Statisticalhealthcare/DH_4086603.

9 Shin D, Oh YH, Eom CS, Park SM. Use of selective serotonin reuptake inhibitors and risk of stroke: a systematic review and meta-analysis. J Neurol 2014;261:686-95. doi:10.1007/s00415-014-7251-9.

10 Coupland C, Dhiman P, Morriss R, Arthur A, Barton G, Hippisley-Cox J. Antidepressant use and risk of adverse outcomes in older people: population based cohort study. BMJ 2011;343:d4551. doi:10.1136/ bmj.d4551.

11 Meier CR, Schlienger RG, Jick H. Use of selective serotonin reuptake inhibitors and risk of developing first-time acute myocardial infarction. BrJ Clin Pharmacol 2001;52:179-84. doi:10.1046/j.0306-5251.2001.01426.x.

12 Monster TB, Johnsen SP, Olsen ML, McLaughlin JK, Sørensen HT. Antidepressants and risk of first-time hospitalization for myocardial infarction: a population-based case-control study. Am J Med 2004:117:732-7. doi:10.1016/i.amjmed.2004.06.027.

13 Schlienger RG, Fischer LM, Jick H, Meier CR. Current use of selective serotonin reuptake inhibitors and risk of acute myocardial infarction. Drug Saf 2004;27:1157-65. doi:10.2165/00002018-200427140-00006.

14 US Food and Drug Administration. FDA Drug Safety Communication. FDA Drug Safety Communication: Abnormal heart rhythms associated with high doses of Celexa (citalopram hydrobromide). 2011. www.fda. gov/Drugs/DrugSafety/ucm269086.htm.

15 Castro VM, Clements CC, Murphy SN, et al. QT interval and antidepressant use: a cross sectional study of electronic health records. BMJ 2013;346:f288. doi:10.1136/bmi.f288.

16 Girardin FR, Gex-Fabry M, Berney P, Shah D, Gaspoz JM, Dayer P. Drug-induced long QT in adult psychiatric inpatients: the 5-year cross-sectional ECG Screening Outcome in Psychiatry study. Am J Psychiatry 2013;170:1468-76. doi:10.1176/appi.ajp.2013.12060860.

17 El-Sherif N, Turitto G. Torsade de pointes. Curr Opin Cardiol 2003;18:6-13. doi:10.1097/00001573-200301000-00002

18 Zivin K, Pfeiffer PN, Bohnert ASB, et al. Evaluation of the FDA warning against prescribing citalopram at doses exceeding $40 \mathrm{mg}$. Am J Psychiatry 2013;170:642-50. doi:10.1176/appi.ajp.2013.12030408.

19 Leonard CE, Bilker WB, Newcomb C, Kimmel SE, Hennessy S. Antidepressants and the risk of sudden cardiac death and ventricular arrhythmia. Pharmacoepidemiol Drug Saf 2011;20:903-13.21796718.

20 Coupland C, Morriss R, Arthur A, Moore M, Hill T, Hippisley-Cox I. Safety of antidepressants in adults aged under 65: protocol for a cohort study using a large primary care database. BMC Psychiatry 2013;13:135. doi:10.1186/1471-244X-13-135.

21 Hill T, Coupland C, Morriss R, Arthur A, Moore M, Hippisley-Cox J. Antidepressant use and risk of epilepsy and seizures in people aged 20 to 64 years: cohort study using a primary care database. BMC Psychiatry 2015:15:315. doi:10.1186/s12888-015-0701-9.

22 Coupland C, Hill T, Morriss R, Arthur A, Moore M, Hippisley-Cox J. Antidepressant use and risk of suicide and attempted suicide or self harm in people aged 20 to 64 : cohort study using a primary care database. BMJ 2015;350:h517. doi:10.1136/bmj.h517.

23 Martinez C, Rietbrock S, Wise L, et al. Antidepressant treatment and the risk of fatal and non-fatal self harm in first episode depression: nested case-control study. BMJ 2005;330:389. doi:10.1136/ bmj.330.7488.389. 
24 Hippisley-Cox J, Pringle M, Hammersley V, et al. Antidepressants as risk factor for ischaemic heart disease: case-control study in primary care. BMJ 2001:323:666-9. doi:10.1136/bmi.323.7314.666.

25 Coupland CA, Dhiman P, Barton G, et al. A study of the safety and harms of antidepressant drugs for older people: a cohort study using a large primary care database. Health Technol Assess 2011;15:1-202, iii-iv. doi: 10.3310/hta15280.

26 Hippisley-Cox J, Coupland C. Risk of myocardial infarction in patients taking cyclo-oxygenase-2 inhibitors or conventional non-steroidal anti-inflammatory drugs: population based nested case control analysis. BMJ 2005;330:1366-74. doi:10.1136/bmj.330.7504.1366.

27 Hippisley-Cox J, Coupland C, Brindle P. Derivation and validation of QStroke score for predicting risk of ischaemic stroke in primary care and comparison with other risk scores: a prospective open cohort study. BMJ 2013;346:f2573. doi:10.1136/bmj.f2573.

28 FDA Drug Safety Communication. FDA Drug Safety Communication: Revised recommendations for Celexa (citalopram hydrobromide) related to a potential risk of abnormal heart rhythms with high doses. 2012. http://www.fda.gov/Drugs/DrugSafety/ucm297391.htm.

29 Altman DG, Andersen PK. Calculating the number needed to treat for trials where the outcome is time to an event. BMJ 1999;319:1492-5. doi:10.1136/bmj.319.7223.1492.

30 Nicholson A, Kuper H, Hemingway H. Depression as an aetiologic and prognostic factor in coronary heart disease: a meta-analysis of 6362 events among 146538 participants in 54 observational studies. Eur HeartJ 2006;27:2763-74. doi:10.1093/eurheartj/ehl338.

31 Pan A, Sun Q, Okereke OI, Rexrode KM, Hu FB. Depression and risk of stroke morbidity and mortality: a meta-analysis and systematic review. JAMA 2011;306:1241-9. doi:10.1001/jama.2011.1282.

32 Taylor D. Antidepressant drugs and cardiovascular pathology: a clinical overview of effectiveness and safety. Acta Psychiatr Scand 2008;118:434-42. doi:10.1111/j.1600-0447.2008.01260.x

33 National Institute for Health and Care Excellence. Depression: the treatment and management of depression in adults. NICE, 2009.

34 Herrett E, Thomas SL, Schoonen WM, Smeeth L, Hall AJ. Validation and validity of diagnoses in the General Practice Research Database: a systematic review. BrJ Clin Pharmacol 2010;69:4-14 doi:10.1111/j.1365-2125.2009.03537.x

35 Khan NF, Harrison SE, Rose PW. Validity of diagnostic coding within the General Practice Research Database: a systematic review. Br J Gen Pract 2010:60:e128-36. doi:10.3399/bjgp10X483562.

36 Hennessy S, Leonard CE, Palumbo CM, Bilker WB, Newcomb C, Kimmel SE. Diagnostic codes for sudden cardiac death and ventricular arrhythmia functioned poorly to identify outpatient events in EPIC's General Practice Research Database. Pharmacoepidemiol Drug Saf 2008;17:1131-6. doi:10.1002/pds.1632.

37 Thanacoody HKR, Thomas SH. Tricyclic antidepressant poisoning cardiovascular toxicity. Toxicol Rev 2005:24:205-14. doi:10.2165/00139709-200524030-00013.

38 Roose SP, Glassman AH, Giardina EG, Walsh BT, Woodring S, Bigger JT. Tricyclic antidepressants in depressed patients with cardiac conduction disease. Arch Gen Psychiatry 1987;44:273-5. doi:10.1001/archpsyc.1987.01800150093011.
39 Blanchette CM, Simoni-Wastila L, Stuart B. Cardiovascular risk of antidepressant use in elderly medicare beneficiaries: comparison by therapeutic class. Ann Epidemiol 2005;15:643-4doi:10.1016/j. annepidem.2005.06.039.

40 Tata LJ, West J, Smith C, et al. General population based study of the impact of tricyclic and selective serotonin reuptake inhibitor antidepressants on the risk of acute myocardial infarction. Heart 2005;91:465-71. doi:10.1136/hrt.2004.037457.

41 Cohen HW, Gibson G, Alderman MH. Excess risk of myocardial infarction in patients treated with antidepressant medications: association with use of tricyclic agents. Am J Med 2000;108:2-8. doi:10.1016/S0002-9343(99)00301-0.

42 Smoller JW, Allison M, Cochrane BB, et al. Antidepressant use and risk of incident cardiovascular morbidity and mortality among postmenopausal women in the Women's Health Initiative study. Arch Intern Med 2009:169:2128-39. doi:10.1001/archinternmed.2009.436.

43 Kimmel SE, Schelleman H, Berlin JA, et al. The effect of selective serotonin re-uptake inhibitors on the risk of myocardial infarction in a cohort of patients with depression. Br J Clin Pharmacol 2011;72:514-7. doi:10.1111/j.1365-2125.2011.04008.x.

44 Sauer WH, Berlin JA, Kimmel SE. Selective serotonin reuptake inhibitors and myocardial infarction. Circulation 2001;104:1894-8. doi:10.1161/hc4101.097519.

45 Oh SW, Kim J, Myung SK, Hwang SS, Yoon DH. Antidepressant use and risk of coronary heart disease: meta-analysis of observational studies. BrJ Clin Pharmacol 2014;78:727-37. doi:10.1111/bcp.12383.

46 Turnheim $\mathrm{K}$. When drug therapy gets old: pharmacokinetics and pharmacodynamics in the elderly. Exp Gerontol 2003;38:843-53. doi:10.1016/S0531-5565(03)00133-5.

47 Castro VM, Gallagher PJ, Clements CC, et al. Incident user cohort study of risk for gastrointestinal bleed and stroke in individuals with major depressive disorder treated with antidepressants. BMJ Open 2012;2:e000544. doi:10.1136/bmjopen-2011-000544.

48 Chen Y, Guo IJ, Li H, Wulsin L, Patel NC. Risk of cerebrovascular events associated with antidepressant use in patients with depression: a population-based, nested case-control study. Ann Pharmacother 2008:42:177-84. doi:10.1345/aph.1K369.

49 Trifirò G, Dieleman J, Sen EF, Gambassi G, Sturkenboom MC. Risk of ischemic stroke associated with antidepressant drug use in elderly persons. J Clin Psychopharmacol 2010;30:252-8. doi:10.1097/ ICP.0b013e3181dca10a.

50 Pan A, Okereke OI, Sun Q, et al. Depression and incident stroke in women. Stroke 2011;42:2770-5. doi:10.1161/STROKEAHA.111.617043.

51 Hung CC, Lin CH, Lan TH, Chan CH. The association of selective serotonin reuptake inhibitors use and stroke in geriatric population. Am J Geriatr Psychiatry 2013;21:811-5. doi:10.1016/j. jagp.2013.01.018.

Appendix

Supplementary tables 